To cite this article: Çetin EHÖ, Çetin MS, Könte HC, Yaman NM, Tak BT, Ekizler FA, Özeke Ö, Topaloğlu S, Aras D. Trigliserit/HDL oranının, koroner arter hastalığı varlığını ve plak morfolojisini öngördürmedeki yeri. Turk J Clin Lab 2019; 10: 467-473.

- Orjinal Makale

\title{
Trigliserit/HDL oranının, koroner arter hastalığı varlığını ve plak morfolojisini öngördürmedeki yeri
}

\section{The predictive value of triglyceride to HDL ratio in determining coronary artery disease and plaque morphology}

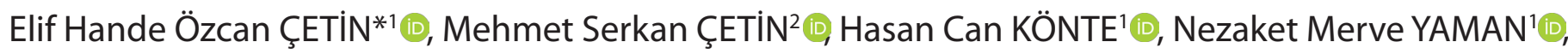

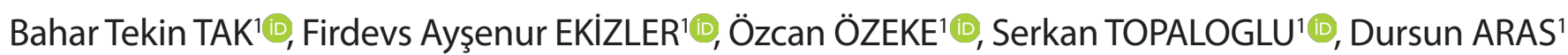

${ }^{1}$ Ankara Şehir Hastanesi, Kardiyoloji Kliniği, Ankara/TÜRKIYE

2 TOBB-ETU Tıp Fakültesi, Kardiyoloji Anabilim Dalı, Ankara/TÜRKiYE

Öz

Amaç: Yeni bir aterojenik indeks olarak, trigliserid HDL oranının (TG/HDL), insülin rezistansı ile ilişkisi ve kardiyovasküler hastalıklarda risk ve prognostik değerlendirmedeki önemi çeşitli çalışmalarda gösterilmiştir. TG/HDL oranı, düşük kardiyovasküler hastalık riskine sahip populasyonda koroner arter hastalığı varlığını öngördürmede faydalı olabilir. Bu çalışmamızda TG/HDL oranının bilgisayarlı tomografik koroner anjiyografi (BTKA) planlanan hastalarda KAH varlığını öngördürmedeki etkinliği ve bu oranın plak morfolojisi, artmış koroner kalsiyum skoru ve stenoz derecesi ile ilişkisini değerlendirmeyi amaçladık.

Gereç ve Yöntemler: Bu retrospektif kesitsel çalışmaya düşük kardiyovasküler riski olup, 2014-2018 tarihleri arasında BTKA'ya refere edilen ardışık 161 hasta dahil edildi.

Bulgular: 90 hastada (\%55.9) KAH saptandı. TG/HDL oranı KAH olan hastalarda yüksekti (2.9 (1.7-4.7)'e karşı 2.6 (1.6-4.1), $\mathrm{p}=0.05$ ). Lojistik regresyon analizinde, yaş ile birlikte, TG/HDL oranında her bir birim artış,KAH ihtimalinde\%28.7 artış ile ilişkili saptandı. Yumuşak plak varlığını ve ciddi darlığı öngördürmede TG/HDL oranı istatistiksel olarak anlamlı bir parametre olarak saptanmadı.

Sonuç: İlerleyen yaşın yanında, TG/HDL oranı KAH varlığını öngördürmede metabolik sendrom varlığından daha etkin bir parametre olarak saptanmış ve etkin bir kardiyometabolik belirteç olduğu gösterilmiştir. Bu kolaylıkla elde edilebilen dislipidemi oranı ile niceliksel değerlendirme sağlanarak daha doğru risk değerlendirilmesi ve böylelikle daha bireyselleştirilmiş tedavi sağlanabilir.

Anahtar kelimeler: Trigliserid/HDL oranı; koroner arter hastalığı; koroner kalsiyum skoru; bilgisayarlı tomografik koroner anjiyografi

Sorumlu Yazar*: Dr. Elif Hande ÖZCAN ÇETIN, Ankara Şehir Hastanesi, Kardiyoloji Kliniği, Ankara/TÜRKIYE

E-posta: dr.elifhande@gmail.com

ORCID: 0000-0001-5969-2345

Gönderim: 09.04.2019 Kabul:03.07.2019

Doi: $10.18663 /$ tjcl.551119 


\begin{abstract}
Aim: As a new atherogenic index, the association of triglyceride to HDL ratio (TG / HDL)with insulin resistance and its significance in risk and prognostic evaluation of cardiovascular diseases have been shown in several studies. TG / HDL ratio may be useful in predicting the presence of coronary artery disease in the population with lowcardiovascular disease risk. In this study, we aimed to evaluate the efficacy of TG / HDL ratio in predicting the presence of CAD and its relationship with plaque morphology, increased coronary calcium score and the degree of stenosisin patients who underwent computed tomographic coronary angiography (CTCA).
\end{abstract}

Material and Methods: This retrospective cross-sectional study included 161 consecutive patients with low cardiovascular disease risk who were referred to CTCA between 2014-2018.

Results: CAD was detected in 90 patients (55.9\%). The TG / HDL ratio was higher in patients with CAD (2.9 (1.7-4.7) vs. 2.6 (1.6-4.1), $\mathrm{p}=0.05)$. In logistic regression analysis, with age, in each one unit increase in TG / HDL ratio was found to associated with $28.7 \%$ increase in probabilty of CAD. TG / HDL ratio was not found to be statistically significant in predicting the presence of soft plaques and severe stenosis.

Conclusıon: With advancing age,TG / HDL ratiowas found to be an effective cardiometabolic marker as a more effective parameter than the metabolic syndrome in predicting the presence of CAD. By providing a quantitative assessment with this readily available ratio of dyslipidemia, a more accurate risk assessment can be achieved and thus more individualized treatment can be provided.

Keywords: Triglyceride to HDL ratio; coronary artery disease; coronary calcium score; computed tomographic coronary angiography

\section{Giriş}

Trigliserid ve kolesterol düzeyleri özellikle de artmış LDL ve açlık TG, kardiyovasküler riskin değerlendirilmesinde yaygın olarak kullanılmaktadır[1]. Bunun yanısıra Total kolesterol ile HDL ve LDL ile HDL oranı gibi oranların tek başına lipid parametrelerine kıyasla kardiyovasküler riskin daha üstün öngördürücüler olarak gösterilmiştir[2]. Trigliserid HDL (TG/HDL) oranı ilk kez Gaziona ve arkadaşları tarafından miyokard infarktüsünün bağımsız, diğer lipid parametreleri ve lipid oranlarından daha üstün bir prediktörü olarak, yeni bir aterojenik indeks olarak ortaya atılmıştır[3]. Rutin açlık lipid profilinin komponentlerinden olan trigliserit ve HDL değerlerinin oranlanmasıyla oluşturulan TG/HDL oranı, kolaylıkla elde edilen bir parametredir. Bu oranın insülin rezistansı ile ilişkisi ve kardiyovasküler hastalıklarda risk ve prognostik değerlendirmedeki önemi çeşitli çalışmalarda gösterilmiştir[4,5].

Aterojenite ile ilişkili olan artmış TG/HDL oranı, bilgisayarlı tomografik koroner anjiyografi (BTKA) ile koroner arter hastalığının (KAH) varlığının araştırılmak istendiği, düşük kardiyovaskuler hastalık riskine sahip populasyonda $\mathrm{KAH}$ varlığını öngördürmede faydalı olabilir. KAH varlığının yanı sıra hastanın kardiyovasküler risk değerlendirmesinde önemli rol oynayan plak morfolojisi ve darlığın ciddiyeti hakkında da fikir verebilir. Bu çalışmamızda TG/HDL oranının BTKA planlanan hastalarda $\mathrm{KAH}$ öngördürmedeki yerini değerlendirmeyi planladık. İkincil amaç olarak bu oranın plak morfolojisi, koroner kalsiyum skoru ve ciddi darlığı öngördürmedeki yerini de değerlendirmeyi amaçladık.

\section{Gereç ve Yöntemler}

Bu retrospektif kesitsel çalışmaya Ocak 2014- Ocak 2018 tarihleri arasında hastanemizde düşük kardiyovasküler riski olup, BTKA' ya refere edilen ardışık 161 hasta dahil edildi. Çalışma protokolü etik kurul tarafından onaylandı. Düşük risk düzeyi Avrupa Kardiyoloji Cemiyeti'nin (ESC) ilgili kılavuzunun önerilerine göre değerlendirildi[6]. Koroner arter hastalığı varlığı önceki çalışmalar doğrultusunda koroner arterde $\% 50$ ve üzeri darlık bulunması olarak tanımlandı. Ciddi $\mathrm{KAH}$ varlığı ise koroner arterde \%75 üzeri darlık olarak kabul edildi. Hipertansiyon varlığı iki ayrı ölçümde sistolik kan basıncının 140 mm Hg ve/veya diyastolik kan basıncının 90 mm Hg üstü olması ya da hastanın halihazırda antihipertansif tedavi alması olarak kabul edildi[7]. Diabetes mellitus açlık plazma glukoz değerinin $126 \mathrm{mg} / \mathrm{dL}$ üzeri olması ya da hastanın halihazırda antidiyabetik tedavi alması olarak kabul edildi[8]. Dislipidemi hastanın total kolesterol değerinin $200 \mathrm{mg} / \mathrm{dL}$ üzeri olması ya da daha önceden dislipidemi tedavisi alması olarak kabul edildi. Son bir ay içinde sigara içmiş olan hastalar aktif içici olarak kabul edildi. Birinci derece akrabalarından kadın olanlar için 65 yaş, erkek olanlar için 55 yaşının altında koroner arter 
hastalığı saptanan hastalarda aile öyküsü varlığı pozitif olarak değerlendirildi. Hastaların kardiyovasküler risk faktörlerinin yanı metabolik sendrom (MetS) varlığı da değerlendirildi. MetS tanısı Ulusal Kolesterol Eğitim Programı kriterlerine göre konuldu[9]. Çalışma için hastanemiz etik kurulundan onay alınmıştır ve çalışmamız Helsinki İlkeler Deklerasyonuna uyularak gerçekleştirilmiştir. Tüm hastalardan bilgilendirilmiş onarm formları alınmıştır.

\section{Laboratuvar Parametreleri}

Hastaların laboratuvar değerleri poliklinik şartlarında en az 8 saatlik açlık sonrası elde edilen kan örneklerinden bakıldı. Hemoglobin ve diğer tam kan değerlendirmesi XN1000(Sysmex,Kobe,Japan) ile yapıldı. Biyokimyasal diğer değerler COBAS C-501 (Roche,Manheim,Germany) ile yapıldı. TG/HDL oranı hastaların rutin lipid profilinden hesaplandı.

\section{Bilgisayarlı Tomografi Parametreleri}

Tüm bilgisayarlı tomografi koroner anjiyografi (BTKA) incelemeleri 64- multidedektör BT tarayıcı (Siemens, Somatom Emotion, Erlangen, Germany) ile yapılmıştır. Çalışmamızda, ilk olarak koroner kalsiyum skorunu değerlendirmek amacıyla kontrastsız görüntüler alındı. Hastaların görüntü kalitesini optimize etmek amacıyla kalp hızları 70 atım/dk olarak hedeflendi ve bu amaçla hastalara iv veya oral beta bloker (metoprolol veya bisoprolol) ile premedikasyon uygulandı. GFR düzeyi de göz önünde tutularak en fazla $100 \mathrm{ml}$ non-iyonik kontrast madde (Omnipaque, Amersham Health, Cork, Ireland) verildi. Görüntüleme prosedürü karinadan kalp bazaline kadar kraniokaudal yönde bir nefes tutma süresince, 64-dedektörlü BT ile yapıldı. Genellikle 1.5 pitch, X-ışını tüpünde $120 \mathrm{kV}$ ve kontrastsızda 300-kontrastlıda 470 miliamper/second (mAs), kesitkalınlığıkontratsız3 mmvekontrastlı0,5 mm olacakşekilde görüntüleme işlemi yapıldı. Çekim boyunca geriye dönük olarak kalp hızı ve elektrokardiyografi (EKG) trasesi segmental rekonstrüksiyon için kaydedildi. Hiçbir hastada işlem sırasında herhangi bir önemli komplikasyon gelişmemiştir. Koroner kalsiyum skoru Agatston ve arkadaşlarının tanımladığı şekilde değerlendirildi[10]. Plakların kalsiyum sınıflandırılması plağın kalsiyum içeriğine göre yapıldı. Kalsiyum içeriği \%50'dan fazla olan plaklar kalsifik, kalsiyum içeriği \%50'den az olanlar mikst ve kalsiyum içeriği olmayanlar yumuşak plak olarak tanımlandı.

\section{Sonlanım noktaları}

Çalışmanın primer son noktası TG/HDL oranının BTKA'da $\mathrm{KAH}$ varlığını öngördürmedeki yerinin gösterilmesiydi. Diğer sonlanım noktaları ise bu oranın plak morfolojisini (yumuşak plaklara karşı kalsifik veya karışık plaklar), yüksek koroner kalsiyum oranını (>100 Agatston skoru) ve ciddi KAH varlığını öngördürmedeki yeriydi.

\section{İstatistiksel Analiz}

Sürekli değişkenlerin normal dağılıp dağılmadığı Kolmogorov Smirnov testi ile belirlendi. Normal dağılıma sahip sürekli değişkenler ortalama土standart sapma (SS), normal dağılıma sahip olmayan sürekli değişkenler medyan ve çeyrekler arası genişlik ve kategorik değişkenler ise hasta sayısı ve yüzde olarak ifade edildi. Iki grup arasındaki ortalamaların karşılaştırmalarda normal dağılıma sahip sürekli değişkenler için Student t-testi, normal dağılıma sahip olmayan değişkenler de ise Mann-Whitney U-testi kullanıldı. Kategorik değişkenler için ki-kare veya Fisher kesin testi uygulandı.

$\mathrm{KAH}$ varlığını öngördürmede lojistik regresyon analizi kullanıldı ve potansiyel öngördürücülerle modeller oluşturuldu. TG/HDL oranının KAH varlığını ayırt etme gücünü değerlendirmek için alıcı işlem karakteristikleri (Receiver operating characteristics, ROC) eğrisi elde edildi. Eğriler arasındaki farklılığı değerlendirmek için DeLong testi ile elde edilen değeri kullanıldı.ROC analiziyle elde edilen eğri altında kalan alanların kıyaslanması optimal sonuçlar sağlamadığından daha ileri yöntemler olan net yeniden sınıflandırma indeksi (net reclassification index) ve entegre ayırdedici iyileşme indeksleri (integrated discrimination improvement) kullanıldı. Burada amaç yeni paremetrenin daha önceki modele eklenmesiyle oluşan yeni modelin ayırt etme gücü eski modelle kıyaslanması olup ve bu çalışmamızda TG/HDL oranının mevcut modele (TG/HDL oranı içermeyen model) eklenmesinin $\mathrm{KAH}$ öngördürmedeki faydası belirlendi. Karar eğrisi analizinde (decision curve analysis) tüm hastalık olasılık eşiklerinde fayda-zarar analizi yapılır ve 'net fayda' elde edilir. Çalışmamızda TG/HDL oranını içeren modelin net faydası ile bu oranı içermeyen modelin net faydaları kıyaslanmış ve grafikle gösterilmiştir.

\section{Bulgular}

90 hastada (\%55.9) KAH saptandı. KAH olan hastalarda diyabet (\%23.3'e karşı \%11.3) ve hipertansiyon sıklığı (\%52.3'e karşı \%27.1) yaklaşık 2 katına çıkmıştı. MetS prevalansı gruplar arasında benzer idi (yaklaşık \%54.0). KAH olan hastalarda antitrombositer ilaç (\%51.4'e karşı \%26.7), beta-bloker (\%43.5'e karşı \%25.0), renin-anjiyotensin antagonisti (\%47.8'e karşı \%25.0) ve statin kullanımı (\%40.0'a karşı \%15.0) $\mathrm{KAH}$ saptanmayan hastalara göre yaklaşık 2 katındaydı(Tablo 1 ). 
Laboratuvar parametrelerinden sadece TG/HDL oranı $\mathrm{KAH}$ olan hastalarda yüksekti (2.9 (1.7-4.7)'e karşı 2.6 (1.6-4.1), $\mathrm{p}=0.05$ ) (Tablo 2).

\begin{tabular}{|c|c|c|c|}
\hline \multirow[t]{2}{*}{ Değişkenler } & \multicolumn{3}{|c|}{ KORONER ARTER HASTALIĞI } \\
\hline & yok & var & P değeri \\
\hline Yaş, yıl & $44.3 \pm 12.1$ & $60.2 \pm 11$ & $<0.001$ \\
\hline Erkek cinsiyet, n(\%) & $54(54.0)$ & $62(63.3)$ & 0.186 \\
\hline Hipertansiyon, n(\%) & $25(25.3)$ & $48(50.0)$ & $<0.001$ \\
\hline Diabetes mellitus, n(\%) & $13(13.0)$ & $21(21.4)$ & 0.116 \\
\hline Hiperlipidemi, n(\%) & $44(44.0)$ & $61(62.2)$ & 0.010 \\
\hline Diabetes mellitus, n(\%) & $43(43.0)$ & $57(58.2)$ & 0.033 \\
\hline Sigara, n(\%) & $24(27.0)$ & $24(33.8)$ & 0.348 \\
\hline Diabetes mellitus, n(\%) & $20(23.5)$ & $37(50.7)$ & $<0.001$ \\
\hline Beta Bloker, n(\%) & $19(22.4)$ & $30(41.7)$ & 0.009 \\
\hline Diabetes mellitus, n(\%) & $19(22.4)$ & $33(45.8)$ & 0.002 \\
\hline $\mathrm{KKB}, \mathrm{n}(\%)$ & $7(8.2)$ & $8(11.1)$ & 0.541 \\
\hline Statin, n(\%) & $13(15.3)$ & $29(39.7)$ & 0.001 \\
\hline $\mathrm{EF}, \%$ & $60.3 \pm 3.3$ & $60.2 \pm 3.9$ & 0.824 \\
\hline
\end{tabular}

\begin{tabular}{|c|c|c|c|}
\hline \multirow{2}{*}{ Değişkenler } & \multicolumn{3}{|c|}{ KORONER ARTER HASTALIĞI } \\
\hline & yok & var & P değeri \\
\hline $\mathrm{EF}, \%$ & $60.3 \pm 3.3$ & $60.2 \pm 3.9$ & 0.824 \\
\hline Glukoz, mg/dL & $101.8 \pm 37.0$ & $111.9 \pm 37.8$ & 0.080 \\
\hline Kreatinin, mg/dL & $0.9 \pm 0.7$ & $0.9 \pm 0.3$ & 0.828 \\
\hline ALT, U/L & $24.2 \pm 12.8$ & $23.6 \pm 16.7$ & 0.794 \\
\hline CRP, mg/L & $2.9(0.5-10.6)$ & $3.9(1.7-12.0)$ & 0.272 \\
\hline Ürik.asit, mg/dL & $5.1 \pm 1.2$ & $5.6 \pm 1.5$ & 0.178 \\
\hline Hemoglobin, g/dL & $14.5 \pm 1.4$ & $14.2 \pm 1.6$ & 0.204 \\
\hline Total kolesterol, mg/dL & $195.6 \pm 43.8$ & $200.4 \pm 50.2$ & 0.524 \\
\hline $\mathrm{LDL}, \mathrm{mg} / \mathrm{dL}$ & $116.2 \pm 41.2$ & $119.7 \pm 40.3$ & 0.587 \\
\hline $\mathrm{HDL}, \mathrm{mg} / \mathrm{dL}$ & $50.8 \pm 17.3$ & $48.3 \pm 14.4$ & 0.313 \\
\hline Trigliserit, mg/dL & $141.3 \pm 77.8$ & $170.2 \pm 141.7$ & 0.125 \\
\hline Trig/HDL oranı & $2.6(1.6-4.1)$ & $2.9(1.7-4.7)$ & 0.050 \\
\hline \multicolumn{4}{|c|}{$\begin{array}{l}\text { Kısaltmalar: ADEI, anjiyotensin dönüştürücü enzim inhibitörü; ALT, } \\
\text { alanin aminotransferaz; ARB, anjiyotensin reseptör blokerleri; CRP, } \\
\text { C-reaktif protein; EF, ejeksiyon fraksiyonu; HDL, yüksek yoğunluklu } \\
\text { lipoprotein; KAH, koroner arter hastalığı; KKB, kalsiyum kanal } \\
\text { blokeri; LDL, düşük yoğunluklu lipoprotein }\end{array}$} \\
\hline
\end{tabular}

Lojistik regresyon analizinde yaş ile (Odds oranı [OO]: 1.117, \%95 Güven Aralığı [GA]: 1.070-1.166, p<0.001) düzeltildiğinde, TG/HDL oranında her bir birim yükseklik \%28.7 artmış KAH şansı (odds) ile ilişkili saptandı (OO: 1.287, \%95 GA: 1.0801.534, $p=0.005$ )(Tablo 3). (Nagelkerke R kare= \%49.2). Sadece yaş ile oluşturulan modelin eğri altında kalan alanı (EAA) 0.834 (\%95 GA: 0.772-0.896, p<0.001) olup ve yaşın yanına TG/HDL katkısıyla oluşturulan ikinci modelin EAA 0.855 (\%95 GA: 0.797-
$0.912, p<0.001)$ idi. İki modelin EAA'ları benzer idi ( $p=0.171)$. Yaş ve TG/HDL oranı olan model sadece yaş ile oluşturulan model ile karşılaştırıldığında net yeniden sınıflandırma indeksinde (net reclassification index) \%2.5'lik anlamlı olmayan ( $p=0.582$ ) ve entegre ayırdedici iyileşmede (integrated discrimination improvement) \%4.3'lük anlamlı bir artış $(p=0.005)$ saptandı. Bunların yanında tek başına ilerleyen yaş yumuşak plak morfolojisi ve 100 Agatston ünite üzeri kalsiyum skorunun öngörücüsü oldu (sırasıyla OO:0.939 ve 1.142). Darlık derecesini öngördürmede ilerleyen yaşın yanında statin kullanımı ve HDL seviyesi anlamlı olarak saptandı (sırasıyla 00:1.089, 2.843 ve 0.957). Karar eğrisi analizinde yaş ve TG/HDL oranı olan model tek başına yaş olan modele göre artmış net fayda ile ilişkiliydi.

\section{Tartışma}

Bu çalışmamızda TG/HDL oranı koroner arter hastalığının varlığını öngördürmede ilerleyen yaş ile birlikte anlamlı bir parametre olarak saptanırken; yumuşak plak varlığı, koroner kalsiyum skoru ve ciddi koroner arter darlığını öngörmede ek bir faydası görülmemiştir. TG/HDL oranının $\mathrm{KVH}$ öngördürmedeki yeri ve bu hastalarda prognozla olan ile ilişskisi daha önce çeşitli popülasyonlarda gösterilmiştir. Bu çalışmada TG/HDL oranı düşük riskli olan popülasyonda da $\mathrm{KAH}$ varlığını öngörmede anlamlı ve rutin değerlendirmede ek faydası olan bir parametre olarak bulunmuştur.Bu çalışmanın diğer bahsedeğer sonucu ise TG/HDL oranın KAH varlığını öngörmede metabolik sendromdan daha etkin bir parametre olarak saptanmış olmasıdır.

Yüksek trigliserid ve düşük HDL arasındaki aterojenik bağlantı önemlidir. Trigliseridden zengin VLDL'nin yüksek düzeyleri lipid değişimi ve lipoliz sırasında küçük-yoğun LDL oluşturmaktadır. Bu molekül aterogenesiste okside-LDL ile ilişkisi ile anahtar rol oynamaktadır. Bu LDL molekülleri dolaşımda akümüle olarak, hızlı katabolize olan küçük-yoğun HDL oluşturmaktadır. Aterojenik halka bu şekilde tamamlanmaktadır[11]. Copenhagen Male çalışmasında trigliserid düzeyi tek başına güçlü bir risk faktörü iken bunun HDL düzeyine göre stratifiye edilmesi, daha artmış doğrulukla risk tahmini sağlamıştır. Takip eden çalışmalarda TG/HDL oranın kardiyovasküler hastalık riskini ve prognozunu gösteren anlamlı bir parametre olduğu gösterilmiştir [12]. Öte yandan non-diyabetik gruplardaki çalışmalar TG/HDL oranının kardiyovasküler risk faktörü olmanın yanı sıra insülin rezistansının da bir göstergesi olduğunu ortaya koymuştur[4.13.14]. Metabolik sendromda diyet tedavisinin etkinliğini değerlendirmede de kullanışlı olduğu gösterilmiştir[15,16]. Bu bağlamda TG/HDL oranı 


\begin{tabular}{|c|c|c|c|c|}
\hline \multicolumn{3}{|c|}{ Tek Değişkenli Analiz } & \multicolumn{2}{|c|}{ Çok Değişkenli Analiz } \\
\hline Değişkenler & $\mathrm{OO}$ (\%95 GA) & $\mathrm{p}$ & $\mathrm{OO}(\% 95 \mathrm{GA})$ & $\mathrm{p}$ \\
\hline Yaş, yıl & $1.117(1.081-1.154)$ & $<0.001$ & $1.117(1.070-1.166)$ & $<0.001$ \\
\hline Erkek cinsiyet & $1.467(0.831-2.591)$ & 0.186 & & \\
\hline Hipertansiyon & $2.960(1.617-5.419)$ & $<0.001$ & & 0.669 \\
\hline Diabetes mellitus & $1.825(0.856-3.890)$ & 0.119 & & 0.408 \\
\hline Hiperlipidemi & $2.098(1.189-3.703)$ & 0.011 & & 0.163 \\
\hline Metabolik Sendrom & $1.843(1.049-3.238)$ & 0.034 & & 0.153 \\
\hline Sigara & $1.383(0.701-2.727)$ & 0.349 & & \\
\hline Antiplatelet & $3.340(1.693-6.590)$ & 0.001 & & 0.404 \\
\hline Beta Bloker & $2.481(1.241-4.960)$ & 0.010 & & 0.980 \\
\hline ADEI/ARB & $2.939(1.475-5.857)$ & 0.002 & & 0.323 \\
\hline KKB & $1.393(0.479-4.048)$ & 0.543 & & \\
\hline Statin, & 3.650 (1.717-7.759) & 0.001 & & 0.058 \\
\hline$E F, \%$ & $0.990(0.903-1.085)$ & 0.823 & & \\
\hline Glukoz, mg/dL & $1.009(0.998-1.019)$ & 0.098 & & 0.542 \\
\hline Kreatinin, $\mathrm{mg} / \mathrm{dL}$ & $1.064(0.609-1.858)$ & 0.828 & & \\
\hline$A L T, U / L$ & 0.997 (0.977-1.018) & 0.793 & & \\
\hline $\mathrm{CRP}, \mathrm{mg} / \mathrm{L}$ & $1.034(0.972-1.100)$ & 0.289 & & \\
\hline Ürik.asit, mg/dL & $1.224(0.912-1.644)$ & 0.179 & & \\
\hline Hemoglobin, $\mathrm{g} / \mathrm{dL}$ & $0.879(0.720-1.072)$ & 0.204 & & \\
\hline Total kolesterol, mg/dL & $1.002(0.996-1.009)$ & 0.521 & & \\
\hline $\mathrm{LDL}, \mathrm{mg} / \mathrm{dL}$ & $1.002(0.994-1.010)$ & 0.585 & & \\
\hline $\mathrm{HDL}, \mathrm{mg} / \mathrm{dL}$ & $0.990(0.970-1.010)$ & 0.315 & & \\
\hline Trigliserit, mg/dL & $1.002(0.999-1.006)$ & 0.159 & & \\
\hline Trig/HDL oranı & $1.097(0.982-1.226)$ & 0.101 & $1.287(1.080-1.534)$ & 0.005 \\
\hline
\end{tabular}

dislipideminin yanı sıra insülin rezistansını da göstermektedir. Bu bilgiler ışığında TG/HDL oranının basit bir dislipidemi ölçeği olmaktan öte hem kardiyovasküler hastalık riskini hem de metabolik riski öngördüren kardiyometabolik bir risk faktörü olduğu söylenebilir.

Çalışmamızın bir takım önemli yönleri detaylı olarak bahsedilmeyi hak etmektedir. Illk olarak düşük riskli populasyonda TG/HDL oranının KAH varlığını öngördürdüğü ortaya konmuştur. Bu sonuç daha önceki kardiyovasküler hastalık riski ile TG/HDL oranı ile ilişkiyi değerlendiren çalışmalarla oldukça benzerdir. Çalışmamızda diğer önemli nokta TG/HDL oranının, NCEP ATP III kriterlerine göre tanımlanmış metabolik sendrom varlığından daha etkin bir parametre olarak saptanmasıdır. Metabolik sendromun detaylı kriterlere göre var yok olarak değerlendirilmesinin risk değerlendirmede doğruluğu düşürdüğü, nicelliksel olarak kategorizasyonun daha etkin olacağı konusunda tartışmalar vardır $[17,18]$. Bizim çalışmamızda TG/HDL oranı NCEP-ATP
III ile tanımlanan metabolik sendrom varlığından $\mathrm{KAH}^{\prime}$ öngördürmede daha etkin bulunmuştur. Nitekim von Bibra ve arkadaşları insülin rezistansını; Sung ve arkadaşları ise yüksek kardiyovasküler riski öngördürmede TG/HDL oranın metabolik sendromdan daha etkin olduğunu göstermişlerdir[17,18]. Bu konuda daha geniş populasyon ve farklı ırklarda doğrulama çalışmalarına intiyaç vardır. Bu şekilde gündelik kullanımda zor olan kriterlerden ziyade basit bir oranla kardiyometabolik riskin değerlendirilmesi ve kategorize edilmesi kolay ve daha doğru bir değerlendirme sağlayacaktır.

Çalışmamızda ikincil sonlanım noktası; TG/HDL oranının yumuşak plak ve ciddi darlık öngördürmedeki etkinliğiydi. Çalışmamızda TG/HDL oranının bu konudaki etkinliği gösterilememiştir. TG/HDL oranının vasküler hasar ile ilişkili olduğu öngörülürken çeşitli çalışmalarda karotis intima media kalınlığı, arteriyel stiffness ve koroner arter hastalığının yaygınlığı ile ilişkisi tespit edilmiştir[19-21]. Yine yüksek TG/HDL oranının, miyokardiyal infarktüs riskinde 
ve kardiyovasküler mortalitede artış ile ilişkili olduğu gösterilmiştir[3,12,22,23]. Çalışmamızda bu sonuçlardan yola çıkarak, yüksek TG/HDL oranın KAH ciddiyeti ve yumuşak plak varlığı ile ilişkili olabileceği hipotezi kurulmuştu. Fakat böyle bir sonuç saptanmadı. Çalışmamızdaki popülasyonumuzun diğer çalışmalardakine kıyasla düşük riskli olması sebebiyle ciddi $\mathrm{KAH}$ veya yumuşak plak saptanan hasta oranı düşüktür. Olasılıkla bu konudaki etkinliği değerlendirmeye yeterli olmamış olabilir. Bu konunun daha fazla hasta sayısı ile araştırılması gerekmektedir.

Çalışmamızın kısıtlılıkları, çalışmamızın retrospektif dizaynın doğasından kaynaklanan birtakım kısıtlılıkları mevcuttur. Bunun yanısıra zamansal olarak TG/HDL oranındaki değişimin ortaya konması, bu değişimin etkilerinin değerlendirilmesi, TG/HDL oranınındiğer kardiyometabolik risk belirteçleri ile korelasyonunun incelenmesi çalışmamızı güçlendirebilirdi.

\section{Sonuç}

İlerleyen yaşın yanında, sadece lipid profilinden elde edilebilen TG/HDL oranı çalışmamızda KAH varlığını öngördürmede NCEP-ATP III kriterleri ile tanımlanmış metabolik sendrom varlığından daha etkin bir parametre olarak saptanmış ve etkin bir kardiyometabolik belirteç olduğu gösterilmiştir. $\mathrm{Bu}$ kolaylıkla elde edilebilen dislipidemi oranı ile niceliksel değerlendirme sağlanarak daha doğru risk değerlendirilmesi ve böylelikle daha bireyselleştirilmiş tedavi sağlanabilir.

\section{Maddi destek ve çıkar ilişkisi:}

Çalışmayı maddi olarak destekleyen kişi/kuruluş yoktur ve yazarların herhangi bir çıkara dayalı ilişkisi yoktur.

\section{Kaynaklar}

1. Bissell MG. Triglycerides and the Risk of Coronary Heart Disease: 10158 Incident Cases Among 262255 Participants in 29 Western Prospective Studies. Yearbook of Pathology and Laboratory Medicine 2008; 329-30.

2. Kinosian B. Cholesterol and Coronary Heart Disease: Predicting Risks by Levels and Ratios. Annals of Internal Medicine1994; 121:641.

3. Gaziano JM et al. Fasting Triglycerides, High-Density Lipoprotein, and Risk of Myocardial Infarction. Circulation 1997; 96: 2520-25.

4. Salazar MR et al. Identifying cardiovascular disease risk and outcome: use of the plasma triglyceride/high-density lipoprotein cholesterol concentration ratio versus metabolic syndrome criteria. Journal of Internal Medicine 2013; 273: 595-601.

5. McLaughlin T et al. Is There a Simple Way to Identify InsulinResistant Individuals at Increased Risk of Cardiovascular Disease? The American Journal of Cardiology 2005; 96: 399-404.
6. 2013 ESC guidelines on the management of stable coronary artery disease. European Heart Journal 2013; 34: 2949-3003.

7. Williams B et al. 2018 ESC/ESH Guidelines for the management of arterial hypertension. Kardiol Pol 2019; 77: 71-159.

8. Kendall D. American Diabetes Association Complete Guide to Diabetes: The Ultimate Home Diabetes Reference. 5th ed., Virginia: American Diabetes Association; 2000.

9. Third Report of the National Cholesterol Education Program (NCEP) Expert Panel on Detection, Evaluation, and Treatment of High Blood Cholesterol in Adults (Adult Treatment Panel III) Final Report. Circulation 2002; 106: 3143-421

10. Agatston AS et al. Quantification of coronary artery calcium using ultrafast computed tomography. Journal of the American College of Cardiology 1990; 15: 827-32.

11. Shepherd J, Packard CJ. (2000) Lipoprotein Metabolism and Atherogenesis. In: Kita T., Yokode M. (eds) Lipoprotein Metabolism and Atherogenesis. Springer, Tokyo

12. Jeppesen J. Triglycerides, High-Density Lipoprotein Cholesterol, and Risk of Ischemic Heart Disease: A View from the Copenhagen Male Study. Metabolic Syndrome and Related Disorders 2003; 1: 33-53.

13. Salazar MR et al. Use of the plasma triglyceride/high-density lipoprotein cholesterol ratio to identify cardiovascular disease in hypertensive subjects. Journal of the American Society of Hypertension 2014; 8: 724-31.

14. Salazar MR et al. Comparison of the abilities of the plasma triglyceride/high-density lipoprotein cholesterol ratio and the metabolic syndrome to identify insulin resistance. Diabetes and Vascular Disease Research 2013; 10: 346-52.

15. Accurso A et al. Dietary carbohydrate restriction in type 2 diabetes mellitus and metabolic syndrome: time for a critical appraisal. Nutrition \& Metabolism 2008; 5: 9.

16. von Bibra $H$, Ströhle A, St. John Sutton M, Worm N. Dietary therapy in heart failure with preserved ejection fraction and/or left ventricular diastolic dysfunction in patients with metabolic syndrome. International Journal of Cardiology 2017; 234: 7-15.

17. von Bibra H, Saha S, Hapfelmeier A, Müller G, Schwarz PEH. Impact of the Triglyceride/High-Density Lipoprotein Cholesterol Ratio and the Hypertriglyceremic-Waist Phenotype to Predict the Metabolic Syndrome and Insulin Resistance. Horm. Metab. Res. 2017; 49: 542-49.

18. Sung K-C, Reaven G, Kim S. Ability of the plasma concentration ratio of triglyceride/high-density lipoprotein cholesterol to identify increased cardio-metabolic risk in an east Asian population. Diabetes Research and Clinical Practice 2014; 105: 96-101. 
19. Hermans MP, Ahn SA, Rousseau MF. The atherogenic dyslipidemia ratio $[\log (\mathrm{TG}) / \mathrm{HDL}-\mathrm{C}]$ is associated with residual vascular risk beta-cell function loss and microangiopathy in type 2 diabetes females. Lipids Health Dis. 2012; 11: 132.

20. Urbina EM et al. Triglyceride to HDL-C Ratio and Increased Arterial Stiffness in Children, Adolescents, and Young Adults. Pedıatrics 2013; 131: 1082-90.

21. da Luz PL, Favarato D, Faria-Neto JR, Lemos $P$, Chagas ACP. High ratio of triglycerides to $\mathrm{HDL}$-cholesterol predicts extensive coronary disease. Clinics 2008; 63: 427-32.
22. Bittner $\mathrm{V}$ et al. The triglyceride/high-density lipoprotein cholesterol ratio predicts all-cause mortality in women with suspected myocardial ischemia: a report from the Women's Ischemia Syndrome Evaluation (WISE). Am. Heart J. 2009; 157: 548-55

23. Wan $\mathrm{K}$ et al. The association between triglyceride/high-density lipoprotein cholesterol ratio and all-cause mortality in acute coronary syndrome after coronary revascularization. PLoS One 2015; 10: 0123521. 